\title{
Piggyback transportation as a factor in ensuring sustainable development of transport links between regions
}

\author{
Laslo Kukla1, Sergey Maksimov2,, , Vladislav Shchekoldin², and Valeria Nazarkina ${ }^{2}$ \\ ${ }^{1}$ Lviv National Agrarian University, 1 Volodymyra Velykoho str., 80381 Dubliany, Ukraine \\ ${ }^{2}$ Novosibirsk State Technical University, 20 K.Marx Avenue, 630073 Novosibirsk, Russia
}

\begin{abstract}
The article discusses piggyback transportation and their role in modern logistics technologies, which make it possible to implement certain elements of the concept of sustainable development of both regional and international economies. The main aspects of the organization of piggyback transportation, their advantages and disadvantages have been studied, the problems of use in the conditions of the Russian Federation have been identified. The lack of experience in their implementation, the insufficient level of interaction between various sectors of the economy were noted as one of the main problems of using piggyback transportation in the formation of logistics chains, as well as the complexity and ambiguity of assessing the effectiveness of their implementation. The paper proposes an approach to assessing the effectiveness of piggyback transportation, based on the use of expert assessment methods, in particular, the Delphi method and the Saati hierarchy analysis method. The features of the implementation of piggyback transportation in the West Siberian region of the Russian Federation are noted.
\end{abstract}

\section{Introduction}

The impact of sustainable development of the transport sector on the region's economy can hardly be overestimated. Transport provides the ability to move people and goods, is a prerequisite for creating a single economic space, the basis of trade infrastructure, has a significant impact on the competitiveness of certain industries in countries and regions [1]. The imperfection of the transport system (bottlenecks, limited multimodality, high tariffs, etc.) negatively affects the efficiency of the country's economy as a whole. And vice versa, the accelerated development of transport infrastructure, the improvement of transport and logistics systems, the introduction of innovative logistics technologies have a significant impact on economic growth as individual regions, countries, and even entire geopolitical unions.

Traditionally, three types of transport prevail in the Russian system of freight transport: road, rail and pipeline, which account for $98.4 \%$ of all freight traffic [2]. Each type of transport is characterized by a specific set of logistic problems that require both operational

\footnotetext{
*Corresponding author: mtsoi@mail.ru
} 
and strategic solutions. Such problems include increased competition among transport, logistics and forwarding, providing transportation services by various modes of transport, both at the regional and international levels; an increase in the volume and range of transported goods; stricter requirements for the speed and quality of cargo delivery; the need to introduce modern technologies for handling and transporting goods, etc.

In addition, the significant shortcomings of existing logistics schemes lead to a significant increase in the cost of transport and logistics costs, which directly affects the volume of transportation and leads to a reorientation of the structure of freight traffic towards the delivery of goods with high added value. In the countries of the European Union, these costs are about $15-17 \%$, and in the Russian Federation from 23 to $40 \%$ [2], which significantly reduces the competitiveness of the domestic transport system and companies in the international market.

The introduction of the concept of sustainable development imposes new requirements on the formation and maintenance of the efficient functioning of logistics systems. In particular, the ideas of "green logistics" imply the need to reduce emissions of harmful substances from vehicles and improve their environmental friendliness. An example of the active implementation of this approach are the countries of the European Union, which regularly impose restrictions and bans on the use of old types of vehicles and encourage the development and implementation of programs for the development of environmentally friendly transport and logistics technologies. Another example is the active work of the PRC government to improve the system of limiting greenhouse gas emissions due to the high level of atmospheric pollution in numerous industrial zones, and in highly urbanized areas of China [3].

For European companies, one of the priorities is to ensure the environmentally friendly transportation. This criterion is met by piggyback transportation, a significant part of which is carried out on the main railways, which are electrified both in the Russian Federation and in Europe, which means minimal emissions of harmful substances. European experience shows that the transfer of transportation from road transport to contrailers can reduce carbon dioxide emissions by $82-84 \%$ [1].

\section{Materials and Methods}

One of the effective ways to solve these problems in the regions of the Russian Federation is, in our opinion, the introduction of so-called piggyback transportation [4], the essence of which is the implementation of the following scheme for the delivery of goods:

1. the trailer loaded with the sender's goods is delivered to the railway station by road;

2. the enlarged cargo units are reloaded onto the railway platform of the train at a railway station equipped with loading and unloading equipment;

3. the train goes to the destination station;

4. at the destination station, the cargo units are unloaded and sent under their own power to the points of destination;

Trailer and piggyback trains are block trains of constant circulation, which move laden to the destination station without re-forming along the route.

To implement such transportation, two schemes can be applied. In the first case, contrailers are transported at uniform rates with equal rights for all participating links of the logistics chain on a contractual basis. With the introduction of the second scheme, railway companies provide transportation services, and the firms interacting with them act as clients paying for their services.

In Russia, the first attempts to organize piggyback transportation were undertaken in 2010 , but even a pilot project was not developed, which became an obstacle to the introduction of technology both in the region and in the country as a whole [5]. Currently, a 
legislative basis for organizing piggyback transportation in Russia has been formed: The Ministry of Transport of the Russian Federation has approved the Rules for the carriage of road trains, caravans, semi-trailers, swap bodies in an empty or loaded state in freight cars by the Ministry of Transport of the Russian Federation, which are the rules for regulating piggyback transportation.

The first official piggyback transportation in the Russian Federation was carried out in December 2018 on the route "Novosibirsk - Moscow". The choice of points of departure and destination of this transportation has a logical rationale, since Moscow is the largest transport hub of the Russian Federation, and Novosibirsk naturally fits into the system of international transportation due to its convenient geographical location, which allows organizing delivery to the Asia-Pacific region (including the PRC), the countries of Central Asia, as well as to European countries.

In addition, in Novosibirsk, on the one hand, it can be formed as an internal Russian route railway piggyback traffic from the western and eastern directions; and international, including from the EU countries and, first of all, from Eastern Europe. On the other hand, in the zone of influence of the Novosibirsk transport and logistics hub there are more than 13.5 million people located within a radius of $750 \mathrm{~km} \mathrm{[4].}$

In the West Siberian region, interest in piggyback transportation has grown significantly in the period 2020-2021. At the same time, the consequences of the spread of coronavirus infection affected since the list of goods for transportation by road was legally limited. In addition, despite the instructions of the Government of the Russian Federation to ensure the unhindered delivery of food, medicine and social goods by truck, some regions tried to impose their own bans on the passage of vehicles on their territory, including on federal highways. At the same time, it is obvious that the drivers of vehicles were exposed to an increased risk of infection and, accordingly, measures for strict quarantine supervision were introduced. This situation led to a redistribution of freight traffic from road transport to rail transport, and piggyback transportation, especially in the option of transporting one trailer without a driver, began to arouse great interest of both government and commercial structures.

Thus, in Novosibirsk there is a combination of possibilities for using main railway routes and ensuring the delivery of these goods by road to end consumers located in local territories.

A significant part of the existing logistic schemes looks exactly like this: first, the delivery of goods by rail to Novosibirsk is carried out, and then transportation to the end user is provided on the principle of the "last mile" by road. However, in practice, such a piggyback transportation mechanism often does not work, since during its implementation it is reloaded from one type of transport to another using warehouses and storage facilities, which significantly increases the cost of the entire transport and logistics operation.

\section{Results and Discussion}

The development of piggyback transportation depends on a whole variety of factors, the identification and assessment of which requires the improvement of existing and development of new methods that ensure the objectivity of the study of the effectiveness of its use, considering modern economic conditions [5].

To evaluate the efficiency and implementation of the technology of piggyback transportation, it will be logical to use the methods of expert evaluation, which allow to form a generalized integral indicator characterizing the state of various elements of piggyback transportation and thus providing the possibility of comparing this transportation with its ideal option (when the value of the integral indicator is equal to the maximum).

To develop an integral indicator, a pool of experts in the field of transport logistics was formed, which included the current members of the Union of Transport Workers, Forwarders 
and Logisticians of Siberia, who were asked to highlight the most significant factors that determine the effectiveness of piggyback transportation. The list thus formed was subjected to primary statistical analysis, as a result of which it was determined that the relevant factors can be grouped into two fundamentally different groups: factors reflecting the quality of the perfect piggyback transportation and factors characterizing the time indicators of piggyback transportation [6].

The factors of the first group included the following (in decreasing order of importance):

1. The degree of environmental friendliness of piggyback transportation.

2. The degree of safety and security of goods during piggyback transportation.

3. The level of regularity of the movement of vehicles.

4. The accuracy of adherence to delivery dates.

5. The ensuring the provision of operational information on the movement of cargo.

6. The ease of passing customs procedures for intermodal transport.

The second group of factors combines such indicators as:

1. The piggyback time by rail.

2. The time spent on loading / unloading vehicles onto a train.

3. The travel times for vehicles according to the "last mile" principle.

4. The time spent on customs operations.

These factors are also ranked in decreasing order of importance.

Following the method of analysis of Saaty hierarchies [7], on the basis of the selected groups of factors, an expression can be constructed to calculate an integral indicator characterizing the efficiency of piggyback transportation as a whole. An example of such an indicator can be the following representation:

$$
Q=\alpha K+(1-\alpha) T^{-1},
$$

where $\alpha$ is a coefficient characterizing the degree of importance of the indicators of the first group in relation to the indicators of the second group, the value of which is estimated based on expert opinions; $\mathrm{K}$ - generalized indicator of the quality of piggyback transportation; $\mathrm{T}$ is the generalized time spent on the implementation of logistics operations associated with the implementation of piggyback transportation.

Note that to ensure the homogeneity of the components included in the integral indicator, in particular, to maintain the same direction of optimization of each of its parts, the time costs are included in it in the form of an inverse value, since the best transportation in this case is considered to be the one that provides the minimum time for its execution, while quality indicators are assumed to require maximization [8].

To calculate generalized indicators of quality and time costs, it is necessary to assess the importance of the factors included in the above groups, for which the Delphi method is applied. At the same time, experts are first proposed to conduct pairwise comparisons of factors on the nine-point Saaty scale [7], then a matrix of pairwise comparisons is compiled, its eigenvector is calculated, corresponding to the maximum eigenvalue of this matrix. If the vector is normalized, then as components it will contain weight coefficients that determine the degree of importance of each of the factors included in the corresponding group. For the first group of factors, denoted $K_{i}, i=1, \ldots, 6$, these weight coefficients $\beta_{i}$ are specified by values, and for the second, containing factors $T_{j}, j=1, \ldots, 4$, the weight coefficients are determined by values $\gamma_{j}$. Then the final version of the integral indicator, which makes it possible to assess the quality of piggyback transportation, will be as follows:

$$
Q=\alpha \sum_{i=1}^{6} \beta_{i} K_{i}+(1-\alpha)\left(\sum_{j=1}^{4} \gamma_{i} T_{i}\right)^{-1} \rightarrow \max .
$$

In practice, the obtained expression can be used both to assess the quality of a specific piggyback transportation, and to analyze the activities of a company that carries out such 
transportation, as well as to optimize logistics chains for the delivery of goods using piggyback transportation. It is possible to use this approach to assess the quality of piggyback transportation in dynamics, considering data on the performed transportation for certain periods of time, by comparing the values of the integral indicator and identifying "bottlenecks" in the organization of these transportation.

\section{Conclusions}

Summing up, it should be noted that an increase in the number of piggyback transportations will allow establishing closer economic ties between regions of Russia, increasing the intensity of interactions at the international level, in particular, with the EU countries, where this type of transportation is well developed and in demand. In addition, their implementation will lead to a reduction in the total transport and logistics costs of both individual links of the logistics chain and the entire logistics system as a whole; to reduce emissions of harmful substances into the environment; to improve the environmental friendliness of transport in general. This is in good agreement with the global goals of sustainable development of regions and international cooperation in general, since the integrated implementation of piggyback transportation technology will provide a reliable and prompt solution to the current problems in the economy of the Russian Federation and in the West Siberian region in particular.

In the context of the global COVID-19 pandemic, it is also an important fact that piggyback transportation not only leads to a reduction in time and an increase in reliability, but also makes it possible to better ensure and control the safety of both shippers, consignees, and the drivers themselves, who carry out part of the road transportation.

At the same time, it should not be forgotten that the direct introduction of piggyback transportation is associated with a variety of diverse (and not only logistic) problems. As noted in the work, these include an imperfect regulatory framework; lack of specialized specialists; lack of a full-fledged methodology for the formation of railway tariffs in the implementation of the piggyback transportation scheme, when the railways act as a carrier; the lack of a universal methodology for assessing the effectiveness of piggyback transportation to optimize the supply chains being built to meet the demand and requirements of consumers for safety, efficiency and environmental friendliness of transportation.

The paper proposes a scheme for assessing the effectiveness of piggyback transportation, considering the influence of two groups of factors: reflecting the quality of perfect transportation and characterizing the time indicators of the implementation of piggyback transportation. At the same time, it is supposed to use the method of expert assessment to identify the most significant of these factors and build an integral indicator, the optimization of which will allow formatting the most effective schemes for organizing piggyback transportation.

\section{References}

1. H. Mannstein, P. Spichtinger, K. A. Gierens, Transportation Research Part D: Transport and Environment, 10(5) (2005)

2. Transport infrastructure and economic growth, Publishing House Perot (2019)

3. H. Li, J. Strauss, H. Shunxiang, L. Lui, Quarterly Review of Economics and Finance, 69 (2018)

4. K.L. Komarov, S.A. Maksimov, "Novosibirsk multimodal transport hub" (2003) 
5. M.V. Ivanov, Development of the transport infrastructure of the region: factors, directions, assessment tools (2017)

6. G. Litvintseva, V. Shchekoldin, E. Schits, Studies on Russian Economic Development, 28(5), 528 (2017)

7. T. Saaty, J. Alexander. New York, Praeger (1989)

8. M. Tsoy, V. Shchekoldin, E. Ushakova, Earth and Environmental Science, 204 (2018) 